\title{
QUEEN'S
UNIVERSITY
BELFAST
}

\section{Effect of Loading, Voltage Difference and Phase Angle on the Synchronisation of a Small Alternator}

Best, R. J., Morrow, D. J., \& Crossley, P. A. (2009). Effect of Loading, Voltage Difference and Phase Angle on the Synchronisation of a Small Alternator. IET Electric Power Applications, 3(6), 531-542.

https://doi.org/10.1049/iet-epa.2008.0248

\section{Published in:}

IET Electric Power Applications

\section{Document Version:}

Peer reviewed version

\section{Queen's University Belfast - Research Portal:}

Link to publication record in Queen's University Belfast Research Portal

\section{Publisher rights}

Copyright 20009, The Institution of Engineering and Technology.

This work is made available online in accordance with the publisher's policies. Please refer to any applicable terms of use of the publisher.

\section{General rights}

Copyright for the publications made accessible via the Queen's University Belfast Research Portal is retained by the author(s) and / or other copyright owners and it is a condition of accessing these publications that users recognise and abide by the legal requirements associated with these rights.

Take down policy

The Research Portal is Queen's institutional repository that provides access to Queen's research output. Every effort has been made to ensure that content in the Research Portal does not infringe any person's rights, or applicable UK laws. If you discover content in the Research Portal that you believe breaches copyright or violates any law, please contact openaccess@qub.ac.uk. 


\title{
Effect of Loading, Voltage Difference and Phase Angle on the Synchronization of a Small Alternator
}

\author{
Robert J. Best ${ }^{1}$, D. John Morrow $^{1}$, Peter A. Crossley ${ }^{2}$ \\ 1 School of Electronic, Electrical Engineering and Computer Science, Queen's University Belfast, Belfast, \\ BT9 5AH, UK, (Email: r.best@qub.ac.uk, dj.morrow@ee.qub.ac.uk) \\ 2 The Joule Centre, The University of Manchester, Manchester, M60 1QD, UK, (Email: \\ p.crossley@manchester.ac.uk)
}

\begin{abstract}
Synchronization of small distributed generation, $30 \mathrm{kVA}$ to $2 \mathrm{MVA}$, employing salient-pole synchronous machines is normally performed within a narrow range of tolerances for voltage, frequency and phase angle. However, there are situations when the ability to synchronize with non-ideal conditions would be beneficial. Such applications include power system islanding and rapid generator start-up. In this paper the physical process and effect of out-of-phase synchronization is investigated both through simulation and experimental tests on a salient-pole alternator. There are many factors that affect synchronization, but particular attention is given to synchronization angle, voltage difference and, as generators will be loaded during islanding, the load angle. The results suggest that it would be acceptable for the maximum synchronization angle of distributed generation to exceed that of current practice. Interesting observations on the nature of out-of-phase synchronization are made, including some specific to small salient-pole synchronous machines. Furthermore, recommendations are made for synchronization under different system conditions.
\end{abstract}

\section{$1 \quad$ Nomenclature}

$\begin{array}{llll}\boldsymbol{E} & \text { Internal e.m.f. } & H & \text { Inertia constant } \\ i & \text { Current } & J & \text { Inertia } \\ L & \text { Inductance } & P & \text { Real power }\end{array}$




$\begin{array}{llll}R & \text { Resistance } & t & \text { Time } \\ T & \text { Torque } & \boldsymbol{V} & \text { Voltage } \\ X & \text { Reactance } & \alpha & \text { Angular acceleration } \\ \theta_{\text {sync }} & \text { Synchronization angle } & \delta & \text { Load angle } \\ \tau & \text { Time constant } & \boldsymbol{\Phi} & \text { Magnetic flux } \\ \Psi & \text { Flux linkage } & \omega & \text { Angular speed }\end{array}$

\subsection{Subscripts and Superscripts}

$\begin{array}{llll}a & \text { Armature } & \text { bus } & \text { Power system bus } \\ d & \text { Direct-axis (armature) } & e & \text { Electrical } \\ f & \text { Field } & k d & \text { Direct-axis damper } \\ k q & \text { Quadrature axis damper } & m & \text { Mechanical } \\ m d & \text { Direct-axis mutual } & m q & \text { Quadrature-axis mutual } \\ q & \text { Quadrature-axis(armature) } & s & \text { Synchronous } \\ , & \text { Transient } & n & \text { Sub-transient }\end{array}$

\section{Introduction}

Synchronization of distributed generation is normally performed within tolerances such as those given by IEEE Std 1547 [1] and Engineering Technical Report (ETR) 113 [2] in table 1. While there is little doubt that it is best to synchronize with minimum voltage, frequency and phase differences, there are certain applications that would benefit from rough synchronization. These include power system islanding schemes [3], and rapid start-up of generators.

Table 1: Typical tolerances for synchronization

\begin{tabular}{ccccc}
\hline & & IEEE std 1547-2003 & & ETR 113 \\
& $<500 \mathrm{kVA}$ & $0.5-1.5 \mathrm{MVA}$ & $1.5-10.0 \mathrm{MVA}$ & Typical relay \\
\hline Phase angle range & $20^{\circ}$ & $15^{\circ}$ & $10^{\circ}$ & $20^{\circ}$ \\
Slip frequency & $0.3 \mathrm{~Hz}$ & $0.2 \mathrm{~Hz}$ & $0.1 \mathrm{~Hz}$ & $0.22 \mathrm{~Hz}$ \\
Voltage difference & 0.1 per unit & 0.05 per unit & 0.03 per unit & $\leq 0.1$ per unit \\
\hline
\end{tabular}


However, out-of-phase synchronization of distributed generation can have undesirable consequences for both the generator and the power system. The high currents can cause thermal and mechanical damage to winding insulation and protection equipment. Sensitive loads can be affected by the voltage deviations that occur as a direct result of the high currents. High mechanical torques stress shaft components such as couplings, gear boxes and crankshafts. Furthermore, large conventional generators are susceptible to resonance of torsional oscillations, due to long shaft lengths and several rotating inertias, greatly increasing the torsional stress at certain points on the shaft [4-7]. This can lead to shaft fatigue life expenditure and failure [8-11].

In spite of the possible consequences of the most severe synchronizing events, it is a requirement that generators be able to withstand a sudden three-phase terminal short-circuit [12], and consequently any event that is of equivalent severity. Additionally, many distributed generators, such as diesel generators, are of a robust construction, and almost always have damper bars on the rotor. Thus sustained torsional oscillation following out-of-phase synchronization is unlikely. While diesel generators are not immune to damage from resonant torsional oscillations [13], the problems that do occur are normally caused by the reciprocating internal combustion engine. This is mitigated by performing torsional vibration analysis and following appropriate design procedures to modify the natural frequency of the system and provide sufficient damping of most oscillations [14].

From the perspective of the power system, it is expected that during exceptional operating circumstances, such as power system islanding, minor inconveniences caused by short-lived voltage deviations would be more acceptable than the alternative of a sustained power outage.

Previous work by the authors investigated out-of-phase synchronization on a small alternator, and the results suggested that synchronization angles could be increased beyond the current tolerances [15]. However, it is also apparent that the process is not just a simple matter of synchronization angle, and that differences exist between synchronizations at equal leading and lagging angles. One factor not previously considered in depth is the load angle. Generators will be partially loaded during power system islanding and, as will be shown, the load angle can have a noticeable effect on the synchronization transient. 
This paper will explore the effect that synchronization angle, generator loading and voltage deviation have on the peak current and torque during synchronization, through simulation and experimental validation on a $31.5 \mathrm{kVA}$ alternator. Other factors that affect the synchronization process will be discussed briefly.

\section{Physical Process of Out-of-Phase Synchronization}

The sudden three-phase short-circuit of an unloaded synchronous machine is well understood [16-18], and can be described using classical two-reaction theory [19]. Others have studied short-circuits on loaded alternators and the effect of sudden terminal voltage changes [20, 21]. The authors have extended this work to provide an explanation of the phenomenon observed during out-of-phase synchronization.

\subsection{Voltage Shift}

Consider an unloaded and level excited three-phase salient-pole alternator, with both a field winding and damper bars on the rotor, being symmetrically synchronized to an infinite bus while out-of-phase. The terminal voltage, $\boldsymbol{V}$, which was originally equal to the internal e.m.f., $\boldsymbol{E}$, shifts to match that of the infinite bus, $\boldsymbol{V}_{\text {bus }}$, as in fig. 1. For analysis, this can be likened to the application of a balanced voltage to the armature terminals, with $v_{q}$ being the voltage change in the $q$-axis direction and $v_{d}$ being the change in the $d$-axis direction. The load angle of the machine, $\delta$, becomes equal to the synchronization angle, $\theta_{\text {sync }}$, with the alternator initially rotating at synchronous speed, $\omega_{s}$.

The plot in fig. 2 shows the resultant voltage shift, and its $d$ - and $q$-axis components, versus synchronization angle for the unloaded, level-excited alternator, along with the resultant voltage shift for a three-phase short-circuit.

The voltage shift encountered during a sudden three-phase short-circuit of an unloaded, level-excited machine is of magnitude $1.0 \mathrm{pu}$ and occurs in the $q$-axis, $v_{q}$. When out-of-phase synchronization occurs, voltage shifts in both the $d$ - and $q$-axis are generally present with values determined by the synchronization angle. At an angle of $60^{\circ}$ the resultant voltage shift is equivalent in magnitude to that of the three-phase short-circuit, $1.0 \mathrm{pu}$. It may be observed from fig. 2 that for out-of-phase synchronization angles less than $90^{\circ}$, the $d$-axis component of voltage shift is greater than that of the $q$-axis. 


\subsection{Theorem of Constant Flux and Synchronization Current}

While the voltage can shift instantaneously, the theorem of constant flux dictates that the flux linking a closed circuit cannot change instantaneously. Immediately following synchronization all the rotor and stator circuits can be considered as closed circuits. The trapped flux will decay when energy is dissipated in $I^{2} R$ losses or from interaction between magnetically coupled circuits, however, initially the trapped flux can be assumed to remain unchanged.

The resultant armature flux consists of the infinite bus flux component, which rotates at synchronous speed, and a fixed trapped flux component, which is proportional to the voltage shift. The trapped flux has a fixed sine wave profile, reflecting the flux linking the armature windings at the time of the event. There are also the rotating trapped fluxes in the rotor field and damper circuits.

As the rotor rotates, the mutual flux linking the circuits changes, even though the flux linking an individual circuit cannot change. Thus, currents must flow in the windings to create an appropriate leakage flux, as illustrated by fig. 3 .

These currents create m.m.f.s that threaten to change the flux linkages in other windings, but this cannot happen. Furthermore, the normal flux paths are no longer available as any path that links another winding will effectively have an infinite reluctance. Thus the flux must follow leakage paths that consist of free space or highly saturated iron within the area enclosed by the windings. These paths have a high reluctance, resulting in higher current to create the same leakage flux, and the effect is observed as a reduction in reactance.

The trapped flux in the rotor creates aperiodic current components in the rotor circuits and, as the rotor rotates, causes fundamental frequency current in the armature winding. The trapped stator flux sets up aperiodic currents in the armature windings, and causes a fundamental frequency current in the rotor, which in turn creates an m.m.f. that is stationary with respect to the stator. This m.m.f. acts on the stator through a path of varying reluctance, caused by saliency, resulting in a double-fundamental frequency current component in the stator. 
Assuming constant flux linkages, the peak armature leakage flux occurs at $180^{\circ}$ rotor rotation from the event, i.e. after 0.01 seconds in a $50 \mathrm{~Hz}$ system. The peak resultant current would also be expected to occur at this time. However, this is not necessarily the case during out-of-phase synchronization as the voltage shift has both $d$ - and $q$-axis components. The flux is transformed to m.m.f. and current through a reluctance that varies due to saliency, in other words, the $d$-axis and $q$-axis reactances are different. The result is that peak resultant current may occur before or after $180^{\circ}$ rotation.

For leading and lagging synchronizations of equal angle, where the machine is unloaded and level excited with an infinite bus, the $v_{q}$ shift is the same for both and the $v_{d}$ shift is equal in magnitude but opposite in sign, as shown in fig. 2 . It is a combination of this sign change and the fact that $q$-axis subtransient reactance is larger than $d$-axis sub-transient reactance that causes the lagging synchronization peak current to occur at less than $180^{\circ}$ rotation after the synchronization event, and the leading synchronization peak current to occur at more than $180^{\circ}$ rotation. As the magnetic energy is dissipated and the trapped flux decreases, the path reluctance and the currents also decrease. In small alternators with short time constants, the overall effect is that the peak current of a lagging synchronization angle is higher than its leading equivalent.

The classical two-reaction machine equation can be used to describe the relation between machine quantities $[19,20]$. A model based on this, together with a first order representation of machine dynamics, has been used for simulation using Mathworks SimPowerSystems [22]. The equations used by the model are presented in the Appendix.

\subsection{Shaft Torque}

The component of electric power that crosses the air-gap will result in torque (1). Electric power is also dissipated in resistance or temporarily stored in magnetic fields.

$T=\frac{3}{2}\left(i_{q} \Psi_{d}-i_{d} \Psi_{q}\right)$

The air-gap torque arises from the tendency of magnetic fields to align, and can be correlated to the interaction of perpendicular flux and current components in (1). As both aperiodic and alternating 
components of current and flux exist following synchronization, then both alternating and aperiodic components of torque will occur [7, 24, 25].

The main torque components consist of a fundamental frequency oscillatory component, a synchronization torque related to the rotor angle, and a unidirectional torque caused by $I^{2} R$ losses. Only $I^{2} R$ losses arising from alternating components of current in the stator and rotor windings cause unidirectional torque $[7,25]$, i.e. losses supplied by energy from the other side of the air-gap. The unidirectional torque always acts to slow the machine, adding to the decelerating synchronizing torque during a leading synchronization and against the accelerating synchronizing torque during a lagging synchronization. Thus the peak torque of leading synchronizations is higher than for lagging synchronizations. In addition, the frequency decrease following rotor leading synchronizations further increases the peak torque, while the frequency increase following rotor lagging synchronizations decreases the peak torque.

\section{$4 \quad$ Experimental and Simulation Results}

Experimental tests were performed on a $31.5 \mathrm{kVA}, 0.8$ power factor, 4-pole, salient-pole alternator, capable of being synchronized at any desired out-of-phase angle onto the $415 \mathrm{~V}, 50 \mathrm{~Hz}$ distribution network at Queen's University Belfast, as indicated by fig. 4. The synchronous machine's exciter field current is supplied by an external source and this current is held constant throughout each test. This permits the tests to be compared with a sudden three-phase short-circuit conducted in accordance with BS EN 60034-4:1995 [26].

The alternator is driven by a vector controlled induction machine. Alternator voltage and current are measured using Hall Effect transducers, and angular acceleration, speed, and position are measured by a rotary encoder on the induction machine. Resultant armature current is calculated from the three phase measurements via the Clark transformation. Alternator data sheet parameters [27] are summarised in the Appendix. The alternator is synchronized close to the in-feed transformer and thus the contribution from system impedance is small. For comparison, a simulation is performed using the Mathworks SimPowerSystems, synchronous machine block; the equations are given in the Appendix. 
The plots of fig. 5(a-j) compare the simulation and experimental results for $60^{\circ}$ leading and lagging synchronizations. The simulated and experimental results differ due to several factors, including the following: parameter inaccuracies, no representation of the brushless exciter, experimental measurement errors, ignoring harmonic content, assuming linear saturation, and modelling the system as a single rotating mass. The manufacturer's quoted parameters are widely used in power system simulation packages incorporating the classical $d q$-method. However, the manufacturer's parameters describe the machine under specific test conditions [28], and thus some discrepancy in the results would be expected.

The mechanical rotor transient, frequency and torque are shown in fig. 5(c-e) and (h-j), using an electrical convention, i.e. $50 \mathrm{~Hz}$ nominal. The error in the mechanical transients can be partly attributed to the rotating system being modelled as a single mass, whereas in reality there is a rubber-in-compression coupling between the induction machine and alternator.

It is difficult to obtain accurate torque measurements, and as a suitable torque gauge was not available the torque was inferred from angular acceleration and inertia using the swing equation, (2). The mechanical transients are measured by an encoder on the induction machine, and the coupling exhibits dynamic torsional stiffness [29], having a lower stiffness at lower torque levels which can result in damped oscillations. At higher torque levels, the system is assumed to be very stiff, permitting the peak torque to be derived. Data sheet and actual system inertia were confirmed to be accurate by a load rejection test.

$$
\Delta T=\frac{\Delta P}{\omega_{m}}=\frac{2}{\text { poles }} J \alpha
$$

Errors in simulated current further increase the discrepancy of torque, due to the torque relationship with the square of current. However, it should be noted that when comparing with the sudden three-phase short-circuit peak torque, the ratios are similar for both experiment and simulation.

\subsection{Rotor Lagging Mains Synchronization}

The lagging synchronization has a higher peak resultant armature current in fig. 5(a) than its leading equivalent in fig. 5(f), as expected from section 3.2, and provides a good match with the simulation.

The field current, fig. 5(b), initially rises then falls, going slightly negative. In $50^{\circ}$ lagging synchronizations, which are not shown, the field current drops to zero but it does not go negative, although 
simulation suggests that it should. Presumably at this point there is not enough trapped flux remaining to induce the voltage necessary to break down either the diode bridge or the varistor in the brushless excitation system $[30,31]$.

\subsection{Rotor Leading Mains Synchronization}

The leading synchronization resultant armature current, in fig. 5(f), has a longer lasting transient, attributed to the more severe mechanical transient in the rotor angle plot of fig. 5(h) and the frequency plot of fig. 5(i) that is caused by the higher peak torque in fig. 5(j). The reason for the higher peak torque in leading synchronizations was discussed in section 3.3.

The field current, fig. 5(g), initially drops below zero, meaning that either the diode bridge or varistor has broken down. The striking difference between the $60^{\circ}$ leading and lagging synchronization field currents arises from a combination of the following: the ratio of $v_{q}$ and $v_{d}$ shifts, the sign change of $v_{d}$ shift between leading and lagging synchronizations, sub-transient saliency, short time constants, and additionally, the field winding's location on the $d$-axis. The result is an initial field current increase during the lagging synchronization and an initial drop in field current during the leading synchronization.

\section{$5 \quad$ Factors that Affect Synchronization}

There are several factors that affect synchronization. Those identified for investigation in this paper are synchronization angle, generator loading and voltage difference.

\subsection{Synchronization Angle}

Consider that a three-phase short-circuit of an unloaded machine has a voltage shift of $v_{q}=-1 \mathrm{pu}$, and $v_{d}=0$ pu. From fig. 2 , the $60^{\circ}$ synchronizations of an unloaded machine have a voltage shift of $v_{q}=-0.5 \mathrm{pu}$ and $v_{d}=-0.866$ pu when lagging, and $v_{q}=-0.5 \mathrm{pu}$ and $v_{d}=+0.866 \mathrm{pu}$ when leading, as indicated by fig. 6 .

The $v_{q}$ shift creates a fundamental frequency armature current with a magnitude defined by $X_{d}{ }^{\prime \prime}$ during the subtransient period, whereas the $v_{d}$ shift creates a similar current with magnitude defined by $X_{q}{ }^{\prime \prime}[20,21]$. Since $X_{d}^{\prime \prime}<X_{q}{ }^{\prime \prime}$ in small salient-pole machines, such as that detailed in the Appendix, events with large $v_{d}$ shifts tend to have lower peak current than those with the same voltage magnitude shift, but a larger $v_{q}$ 
component. The result being a larger peak current during the sudden three-phase short-circuit than during either $60^{\circ}$ synchronization.

Now consider the sign change of the $v_{d}$ shift between the $60^{\circ}$ synchronizations. As the current in the armature winding transforms to the required leakage flux through a reluctance which is dependent upon saliency, the differing sign of the $v_{d}$ shift causes the time of expected peak current to be different in leading and lagging synchronizations. Peak current occurs earlier in the $60^{\circ}$ lagging synchronization than the $60^{\circ}$ leading synchronization. However, when the short time constants of the small salient-pole machine are considered, the $60^{\circ}$ lagging synchronization peak current will be larger than that of the $60^{\circ}$ leading synchronization, as observed in fig. 5(a) and fig. 5(f).

Fig. 7(a) shows the peak current by synchronization angle for experimental tests and simulation. There is a good correlation. The peak three-phase short-circuit current is also plotted, again from both experiment and simulation. Fig. 7(b) shows the simulated and experimentally obtained peak torque, where again, reasonably good correlation is observed.

The shaded areas of fig. 7(b) represent the region where pole-slipping arises in the simulation and it is probable that this would occur in the actual system too. The simulation suggests that lagging synchronizations of over $90^{\circ}$ could be performed without the system going temporarily unstable. This illustrates the higher electrical system stiffness during transient periods, caused by very low transient and sub-transient reactances, and exacerbated by saliency.

Fig. 7(a) and fig. 7(b) further illustrate the difference between leading and lagging synchronizations, as previously discussed. These results are interesting as they suggest that the synchronization window could be skewed to facilitate a trade-off between peak torque and current for synchronization. However, there are other factors that affect the synchronization characteristic, some of which are now considered.

\subsection{Generator Loading}

Generators are normally synchronized to the system off-load, however during power system islanding the generator will be supplying the local load. An increased load angle will change the $v_{d}$ and $v_{q}$ components of voltage shift at synchronization, and thus affect the transient. 
Consider the special case of a $60^{\circ}$ lagging synchronization with a load angle of $30^{\circ}$, in fig. $8($ a). The voltage shift will all be in the $v_{d}$ direction, as opposed to fig. 6(a) for the unloaded machine, where both $v_{d}$ and $v_{q}$ voltage shift components are evident. Thus as $X_{d}{ }^{\prime \prime}<X_{q}{ }^{\prime \prime}$, this causes lower peak current and torque in the small alternator. Fig. 8(b) shows a $60^{\circ}$ leading synchronization with a $30^{\circ}$ load angle. Compared with fig. 6(b) there is a larger $v_{q}$ shift, leading to a larger peak current and torque.

The effect of load angle on the peak current and torque may be observed in fig. 9(a). and fig. 9(b) respectively. Experimental tests are compared with simulated results. In the plots, load current and torque have been included, hence the offset when synchronizing on-load at $0^{\circ}$. During the experimental tests the total alternator current has been measured directly. The alternator air-gap torque is derived, as two components, from the pre-synchronization alternator power output and the dynamic behaviour of the rotor. The former is determined by the load torque while the latter is calculated using (2). The load torque always acts to slow the machine, adding to the unidirectional component of torque.

The simulation and test results show good correlation. They suggest that increasing the load angle of the machine slightly reduces the current difference between leading and lagging synchronizations of the same angle. This is because the load angle tends to increase the $v_{d} / v_{q}$ shift ratio in lagging synchronizations, and reduce it in leading synchronizations. The results also suggest that peak torques for leading synchronizations and low angle lagging synchronizations are increased by machine loading, a consequence of the higher peak current during leading synchronizations and of the load torque. The modification to the torque characteristic, observed in fig. 9(b), is more pronounced than the effect on peak current in fig. 9(a).

\subsection{Voltage Difference}

The voltage magnitudes may not be equal at the point of common coupling between the two systems. However, they should not go beyond the statutory limits during normal operation.

In fig. 10, with a zero synchronization angle, the alternator terminal voltage is less than the infinite bus voltage and the voltage shift occurs in the positive $v_{q}$ direction. Theoretically, the transient should appear like that of the sudden three-phase short-circuit of an unloaded machine, but with the current flow being into the alternator. 
Fig. 11(a) and fig. 11(b) show how changing the voltage magnitude of the island relative to the main power system affects the current and torque observed. Simulation results are compared with those from experimental tests. In all cases the main power system voltage magnitude is 1.0 per unit.

Any voltage difference serves to increase the peak current and torque at synchronization angles close to zero degrees. A lower alternator terminal voltage tends to reduce the peak current and torque at larger angles. This is because the resultant synchronization voltage shift and thus the amount of trapped flux are affected, in this case reduced, by changing the alternator terminal voltage magnitude.

The same can be said for the mains voltage. If it is below nominal, then the event will be less severe, but if the mains voltage is above nominal then peak torque and current will be increased. Even so, the mains voltage should be within \pm 0.1 per unit of nominal to remain within statutory voltage limits.

\subsection{Other Factors}

There are a number of other factors that affect the synchronization characteristic.

\subsubsection{Frequency Difference}

The frequency difference is not expected to be large when synchronizing islanded power systems to the main power system, because power quality requires the frequency to be maintained close to nominal.

The additional kinetic energy in a fast rotor can aid a lagging synchronization and hinder a leading synchronization. The opposite is the case for a slow rotor. Any deviation of rotor frequency following synchronization will cause asynchronous damping currents and torques. This condition is normally corrected by the asynchronous torques, completing the synchronization process, otherwise asynchronous operation and pole slipping will occur.

\subsubsection{Alternator Construction}

Saliency, in combination with the short time constants of small salient-pole machines, will result in appreciable peak current differences between leading and lagging synchronizations. Large salient-pole machines and cylindrical machines should not exhibit this effect so strongly. 


\subsubsection{Time Constants and Generator Rating}

Simulation of out-of-phase synchronizations on salient-pole alternators of up to 2.25 MVA show similar results, indicating that the experimental tests are representative for alternators in this range. However some differences occur as generator rating increases, which are indicated by fig. 12 and normalised to the short-circuit peak values. Parameters for the alternators are provided in the Appendix.

The longer electrical time constants, characteristic of machines with higher rating, prolong the current and voltage transients following synchronization, but lessen the difference between the peak currents of leading and lagging synchronizations, making them more symmetrical as in fig. 12(a). The relationship between lagging synchronization and short-circuit peak current remains similar.

Higher inertia tends to reduce the asymmetry between leading and lagging peak torque, raising the peak torque achieved at smaller angles in the process, shown in fig. 12(b). This can largely be attributed to the longer electrical time constants of larger machines. In particular, this could have implications for the leading synchronization angle limit. Machines with larger inertia constants, typically of higher rating, are less likely to pole-slip during disturbances, assuming sufficient damping. Torque asymmetry always remains due to reasons discussed in section 3.3.

\subsubsection{System Impedance}

The system impedance of the power line and transformers connecting the synchronous machine to the infinite bus affect the synchronization transient. A high system reactance will reduce the peak current and torque $[7,25]$. The system resistance can increase the unidirectional torque, but also reduces the armature time constant [25].

The presence of system impedance causes the alternator terminal voltage magnitude to fluctuate during synchronization. If this is a large machine, or there are many small machines in the island, a large voltage deviation can result. Voltage deviations are of concern because of the effect on power system loads, especially computer loads and control equipment. A voltage rise is possible during rotor leading synchronizations when power flow is initially into the main power system. 


\section{Discussion}

It is desirable to have a smooth transition between islanded and grid connected operation to maintain high power quality and to reduce the thermal and mechanical stresses on machines. However, ideal conditions cannot always be met.

It has been demonstrated that many factors affect the synchronization process. It is now possible to make some recommendations regarding the maximum synchronization angles of distributed generators with robust construction, such as diesel generators.

Given that generators are designed to withstand a three-phase short-circuit, the associated peak current and torque can be used as a benchmark. Nevertheless, this decision must be revised to reflect the implication on the life of the plant.

Table 2 provides the synchronization angles equivalent to a three-phase short-circuit for the unloaded $31.5 \mathrm{kVA}$ machine at 1.0 pu voltage, and table 3 does the same for the machine at $50 \%$ rated load. Note that [12] states that the generator should be fit for service following a short-circuit when fully-loaded and at $1.05 \mathrm{pu}$ voltage, which would be slightly more severe than the benchmark used here.

Table 2: Synchronization limits for unloaded $31.5 \mathrm{kVA}$ machine at $100 \%$ of short-circuit values

\begin{tabular}{ccc}
\hline & Lagging & Leading \\
\hline Current & $65^{\circ}$ & $95^{\circ}$ \\
Torque & $105^{\circ}$ & $\mathbf{6 0 ^ { \circ }}$ \\
\hline
\end{tabular}

Table 3: Synchronization limits for $31.5 \mathrm{kVA}$ machine at $50 \%$ rated load and $100 \%$ of short-circuit values

\begin{tabular}{ccc}
\hline & Lagging & Leading \\
\hline Current & $\mathbf{7 0 ^ { \circ }}$ & $75^{\circ}$ \\
Torque & $120^{\circ}$ & $\mathbf{5 0}^{\circ}$ \\
\hline
\end{tabular}

Since leading synchronization torques are higher and machine loading further increases leading peak torque, it would be possible to bias the synchronization angle set-point towards rotor lagging angles to 
maximise the window for synchronization. This has previously been suggested for large conventional generation [32].

Work on distributed generators of higher ratings, different construction, i.e. cylindrical machines, or induction machines, would be interesting. The effect of voltage deviations, caused by synchronization, on the power system could also be investigated further.

\section{Conclusion}

Out-of-phase synchronization is a complex issue with many factors affecting the peak current and torque. Thus it is difficult to define a universal set of synchronization limits. Following experimental tests on a $31.5 \mathrm{kVA}$ alternator, accompanied by Mathworks SimPowerSystems simulations, it is the contention of the authors that for distributed generation of robust construction, synchronization angles could be increased beyond their current limits, even if this is only allowed during exceptional circumstances such as power system islanding and rapid generator start-up. As a generalisation, up to $\pm 60^{\circ}$ may be considered acceptable.

This paper has discussed the differences between leading and lagging synchronizations. Peak torque is higher for leading synchronizations, due to the presence of a unidirectional torque that acts to slow the machine, and is exacerbated by associated rotor frequency transients. A characteristic which is particularly noticeable in small salient-pole machines is that the peak current is higher for lagging synchronizations, caused by a combination of the $d$-axis voltage shift direction, short time constants and saliency. It is also interesting to note the striking difference between the field currents of leading and lagging synchronizations.

Generator loading changes the $d$-axis and $q$-axis components of voltage shift, and alters the synchronization characteristic. The reason being that in a salient-pole alternator, where $X_{d}^{\prime \prime}<X_{q}^{\prime \prime}$, a $v_{d}$ shift results in lower peak current than an equivalent $v_{q}$ shift. The most significant consequence is that generator loading further increases the peak torque of leading synchronizations, indicating that it would be beneficial to bias synchronization windows towards lagging angles.

Any alternator-to-bus voltage difference will increase peak current at synchronization angles around $0^{\circ}$. At larger angle synchronizations a low alternator voltage can reduce the voltage shift, and thus the 
trapped flux, making the synchronization transient less severe. Reducing the alternator voltage could allow synchronization windows to be increased further.

The effect of other factors on synchronization has been discussed, namely, frequency difference, alternator construction, alternator rating and system impedance.

\section{Acknowledgements}

R. Best wishes to thank Kelman Ltd, the Department for Employment and Learning (DEL) and the EPSRC Supergen AMPerES consortium for their financial support.

\section{References}

[1] IEEE Standard 1547-2003: 'IEEE standard for interconnecting distributed resources with electric power systems', 2003.

[2] UK Electricity Association, 'Engineering Technical Report (ETR) No. 113: Notes of guidance for the protection of embedded generating plant up to $5 \mathrm{MW}$ for operation in parallel with public electricity suppliers' distribution system', 1995

[3] Best, R. J., Morrow, D. J., McGowan, D. J., and Crossley, P. A.: 'Synchronous islanded operation of a diesel generator’, IEEE Trans. Power Syst., 2007, 22, (4), pp. 2170-2176, 2007

[4] Stojanovic, D., Petrovic, D., and Mitrovic, N.: 'Torsional torques of big turbine-generator shafts due to malsynchronization', Proc. 10th Mediterranean Electrotechnical Conf. (MELECON 2000), Lemesos, Cyprus, May 2000, 3, pp. 1051-1054

[5] Hammons, T. J.: 'Stressing of large turbine generators at shaft couplings and LP turbine final stage roots following clearance of grid system faults and faulty synchronization', IEEE Trans. Power App. Syst., 1980, PAS-99, (4), pp. 1652-1662

[6] Cudworth, C.J. and Smith, J. R.: 'Steam turbine generator shaft torque transients: a comparison of simulated and test results', IEE Proc., Part C (Gener., Transm., Distrib.), 1990, 137, (5), pp. 327-334

[7] Wood, A. J.: 'Synchronizing out of phase', Trans. AIEE, Part III (Power App. and Syst.), 1957, 76, (29), pp. 1-8 
[8] Abolins, A., Lambrecht, D., Joyce, J. S., and Rosenberg, L. T.: 'Effect of clearing short circuits and automatic reclosing on torsional stress and life expenditure of turbine-generator shafts', IEEE Trans. Power App. Syst., 1976, PAS-95, (1), pp. 14-25

[9] Chyn, C., Wu, R. -C., and Tsao, E. -P.: 'Torsional fatigue of turbine-generator shafts owing to network faults', IEE Proc., Gener., Transm., Distrib., 1996, 143, (5), pp. 479-486

[10] Jackson, M. C., Umans, S. D., Dunlop, R. D., Horowitz, S. H. and Parikh, A. C.: 'Turbine-generator shaft torques and fatigue, part 1: simulation methods and fatigue analysis', IEEE Trans. Power App. Syst., 1979, PAS-98, (6), pp. 2299-2307

[11] Dunlop, R. D., Horowitz, S. H., Parikh, A. C., Jackson, M. C. and Umans, S. D.: 'Turbine-generator shaft torques and fatigue, part 2: Impact of system disturbances and high speed reclosure', IEEE Trans. Power App. Syst., 1979, PAS-98, (6), pp. 2308-2328

[12] IEEE Standard C50.13-2005: 'IEEE standard for cylindrical-rotor $50 \mathrm{~Hz}$ and $60 \mathrm{~Hz}$ synchronous generators rated 10 MVA and above', 2005

[13] Craighead, I. A., and Gray, T. G. F.: 'Investigation of diesel generator shaft and bearing failures', Proc. Inst. Mech. Eng., Part K (J. Multi-Body Dynamics), 2004, 218, (K3), pp. 153-158

[14] Mahon, L. L. J.: 'Diesel Generator Handbook', (Butterworth - Heinemann, Oxford, 1992)

[15] Best, R. J., Morrow, D. J. and Crossley, P. A.: 'Out-of-phase synchronization of a small alternator', Proc. IEEE Power Eng. Soc. General Meeting 2007, Tampa Bay, USA, June 2007, pp. 1-7

[16] Sarma, M. S.: 'Electric Machines: steady-state theory and dynamic performance', (West Publishing Company, St. Paul, 1995, 2nd edn.)

[17] Fitzgerald, A. E., Kingsley, C., and Umans, S. D.: 'Electric Machinery', (McGraw - Hill, London, 1992, 5th edn. in SI units)

[18] Say, M. G.: 'Alternating Current Machines', (Longman Science and Technical, Harlow, 1992, 5th edn.)

[19] Park, R. H.: 'Two-reaction theory of synchronous machines, generalized method of analysis - Part 1', Trans. AIEE, 1929, 48, pp. 716730

[20] Adkins, B., and Harley, R G.: 'The general theory of alternating current machines: application to practical problems', (Chapman and Hall, London, 1975) 
[21] Adkins, B.: 'Transient theory of synchronous generators connected to power systems', Proc. IEE, 1951, 98, (64), pp. 510-528

[22] Krause, P. C., Wasynczuk, O, and Sudhoff, S. D.: 'Analysis of electric machinery and drive systems’, (IEEE Press - John Wiley \& Sons, Piscataway, 2002, 2nd edn.)

[23] Kamwa, I., Pilote, M., Carle, H., Viarouge, P., Mpanda-Mabwe, B., Crappe, M., 'Computer software to automate the graphical analysis of sudden short-circuit oscillograms of large synchronous machines’, IEEE Trans. Energy Convers., 1995, 10, (3), pp. 399-406

[24] Mehta, D. B., and Adkins, B.: 'Transient torque and load angle of a synchronous generator following several types of system disturbance', Proc. IEE, Part A, Power Eng., 1960, 107, (31), pp. 61-74

[25] Kirschbaum, H. S.: 'Transient electrical torques of turbine generators during short circuits and synchronizing', Trans. AIEE, 1945, 64, pp. 65-70

[26] BS EN 60034-4:1995: 'Rotating electrical machines: part4. methods for determining synchronous machine quantities from tests'

[27] Leroy Somer: 'Alternators: LSA 42.2 - 4 pole - three phase electrical and mechanical data', Available: http://www.lerosomer.com, accessed October 2008

[28] Tindall, C. E., Martin, J. P., Morrow, D. J., Calvert, P. A. J.: 'Transient characteristics of small salient-pole alternators', IEEE Trans. Energy Convers., 1996, 11, (3), pp. 539-546

[29] Needham, P.: 'Chapter 6: elastomeric element couplings', in Neale, M. (Ed.)., Needham, P., and Horrell, R.: 'Couplings and shaft alignment', (Professional Engineering Publishing Limited, Bury St. Edmunds, 1991), pp. 51-73

[30] Kabir, S. M. L., Shuttleworth, R.: 'Brushless exciter model', IEE Proc., Gener., Transm., Distrib., 1994, 141, (1), pp. 61-67

[31] Martin, J. P., Tindall, C. E.: 'Non-invasive technique for determining parameter values from the sudden short-circuit test data of brushless alternators', IEEE Trans. Energy Convers., 2000, 15, (3), pp. $245-250$

[32] Krause, P. C., Hollopeter, W. C., Triezenberg, D. M., and Rusche, P. A.: 'Shaft torques during outof-phase synchronization', IEEE Trans. Power App. Syst., 1977, PAS-96, (4), 1318-1323 
[33] The MathWorks, TransÉnergie Technologie, Hydro-Québec: 'SimPowerSystems, For Use with Simulink, User's Guide, Version 3', Available: http://www.mathworks.com, accessed January 2009

\section{Appendix}

The Mathworks Simpowersystems blockset is used for simulation of out-of-phase synchronizations. It incorporates a five-coil two-axis equivalent machine representation of a salient-pole alternator, expressed using equations (3) to (12), [22, 33]. A single-order mechanical system is used and expressed as (13). Mechanical damping is ignored in the simulation. The inertia constant, $H$, is calculated from the polar moment of inertia using the machine VA rating and nominal mechanical speed (14).

$$
\begin{aligned}
& V_{d}=R_{a} i_{d}+\frac{d}{d t} \Psi_{d}-\omega \Psi_{q} \\
& V_{q}=R_{a} i_{q}+\frac{d}{d t} \Psi_{q}+\omega \Psi_{d} \\
& V_{f}=R_{f} i_{f}+\frac{d}{d t} \Psi_{f} \\
& V_{k d}=R_{k d} i_{k d}+\frac{d}{d t} \Psi_{k d} \\
& V_{k q}=R_{k q} i_{k q}+\frac{d}{d t} \Psi_{k q} \\
& \Psi_{d}=L_{d} i_{d}+L_{m d}\left(i_{f}+i_{k d}\right) \\
& \Psi_{q}=L_{q} i_{q}+L_{m q} i_{k q} \\
& \Psi_{f}=L_{f} i_{f}+L_{m d}\left(i_{d}+i_{k d}\right) \\
& \Psi_{k d}=L_{k d} i_{k d}+L_{m d}\left(i_{d}+i_{f}\right) \\
& \Psi_{k q}=L_{k q} i_{k q}+L_{m q} i_{q} \\
& \Delta \omega_{m}(t)=\frac{1}{2 H} \int_{0}^{t}\left(T_{m}-T_{e}\right) d t \\
& H=\frac{J\left(\omega_{m}\right)^{2}}{2 \times V A(b a s e)}
\end{aligned}
$$

The data sheet parameters of the 4-pole test alternator [27] on a $31.5 \mathrm{kVA}$ and $400 \mathrm{~V}$ base are summarised in table 4. Grid synchronization is performed at a base of $415 \mathrm{~V}$, and parameters are scaled for the simulation. Note that $\tau_{q}{ }^{\prime \prime}$ is assumed equal to $\tau_{d}{ }^{\prime \prime}$, and the inertia is that of the coupled alternator and vector controlled induction machine. Parameters for the $250 \mathrm{kVA}$ and $2250 \mathrm{kVA}$ alternators simulated in section 5.4.3 are also provided; the inertia is for alternator only. 
Table 4: Alternator parameters, on a $400 \mathrm{~V}$ base

\begin{tabular}{cccc}
\hline Symbol & $31.5 \mathrm{kVA}$ & $250 \mathrm{kVA}$ & $2250 \mathrm{kVA}$ \\
\hline$X_{d}(\mathrm{pu})$ & 2.2 & 3.3 & 2.78 \\
$X_{q}(\mathrm{pu})$ & 1.1 & 2.0 & 1.67 \\
$X_{d}{ }^{\prime}(\mathrm{pu})$ & 0.118 & 0.155 & 0.204 \\
$X_{d}^{\prime \prime}(\mathrm{pu})$ & 0.059 & 0.093 & 0.106 \\
$X_{q}{ }^{\prime \prime}(\mathrm{pu})$ & 0.084 & 0.115 & 0.132 \\
\hline$t_{d}{ }^{\prime}(\mathrm{s})$ & 0.030 & 0.100 & 0.263 \\
$t_{d}{ }^{\prime}(\mathrm{s})$ & 0.003 & 0.010 & 0.026 \\
$t_{a}(\mathrm{~s})$ & 0.004 & 0.015 & 0.048 \\
\hline$J\left(\mathrm{kgm}^{2}\right)$ & $0.62^{*}$ & 2.5 & 59 \\
\hline
\end{tabular}

* Inertia of coupled alternator and vector controlled induction machine 


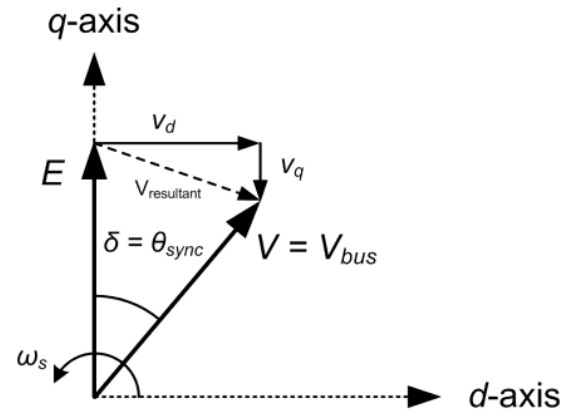

Fig. 1 Pre-synchronization conditions, with rotor leading mains 


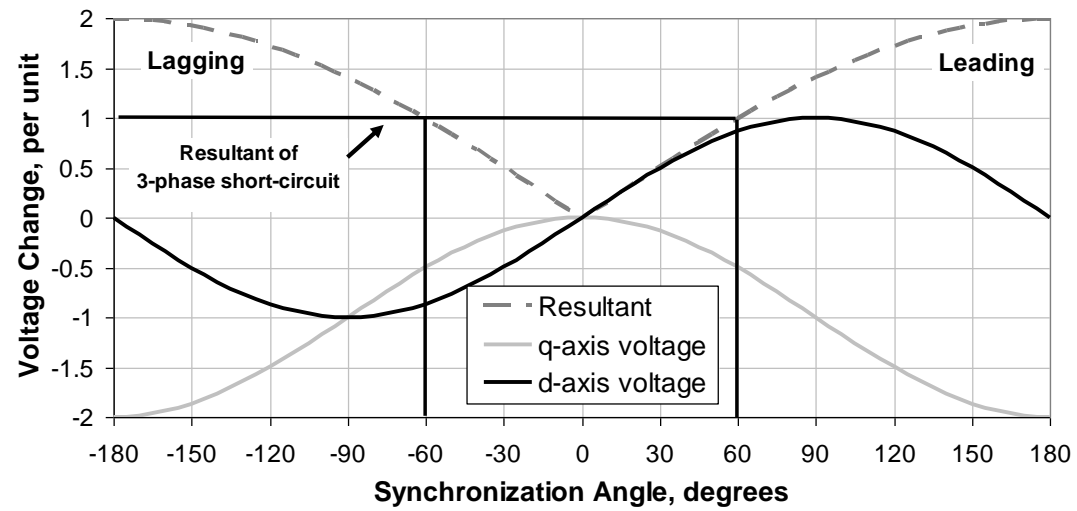

Fig. 2 The $d, q$ and resultant components of voltage shift by synchronization angle for an unloaded machine level-excited with the infinite bus 


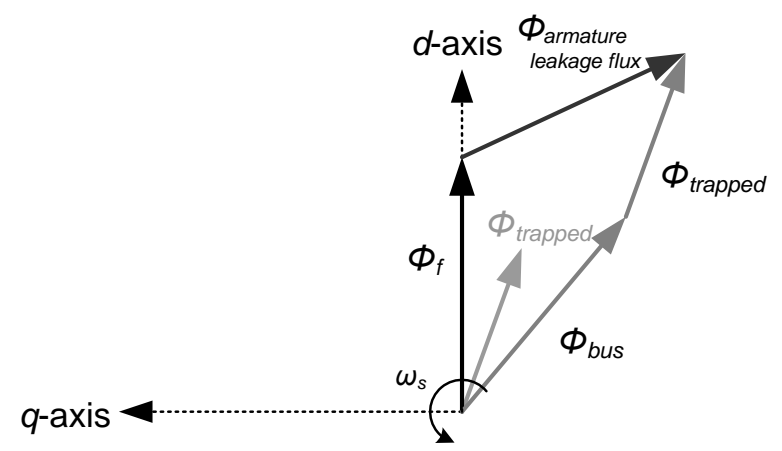

Fig. 3 Armature flux components at $90^{\circ}$ rotation after synchronization 


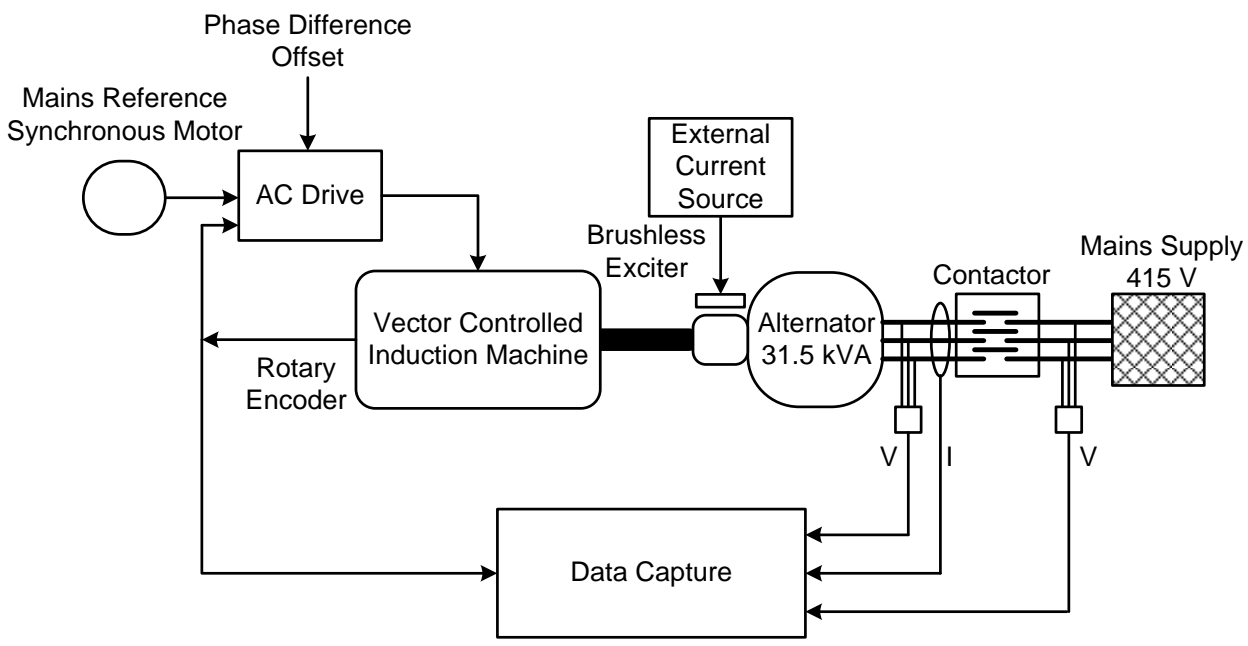

Fig. 4 Diagram of $31.5 \mathrm{kVA}$ alternator test-bed 


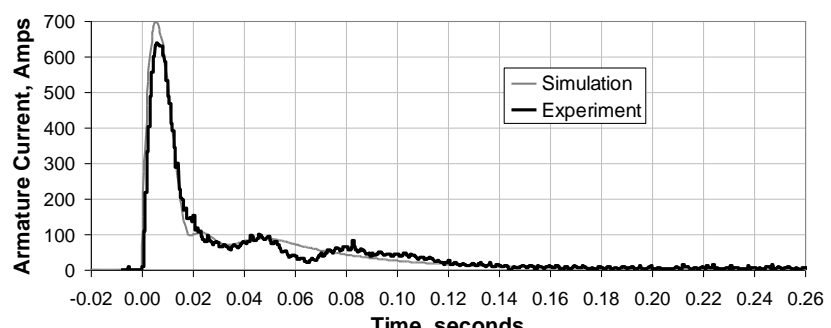

(a)

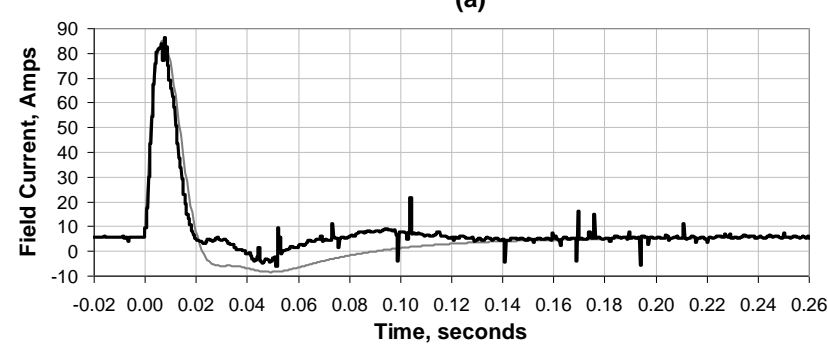

(b)

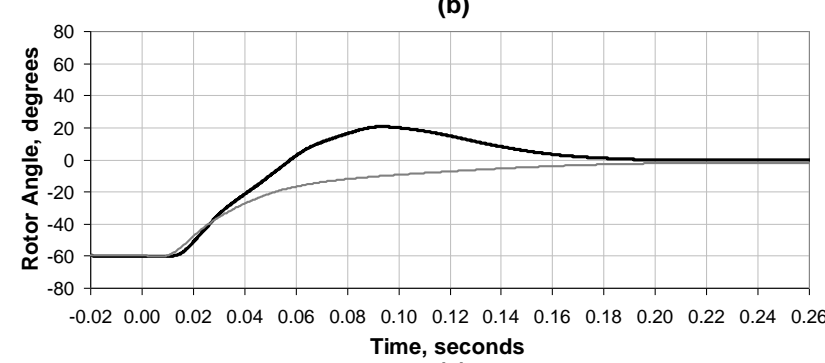

(c)

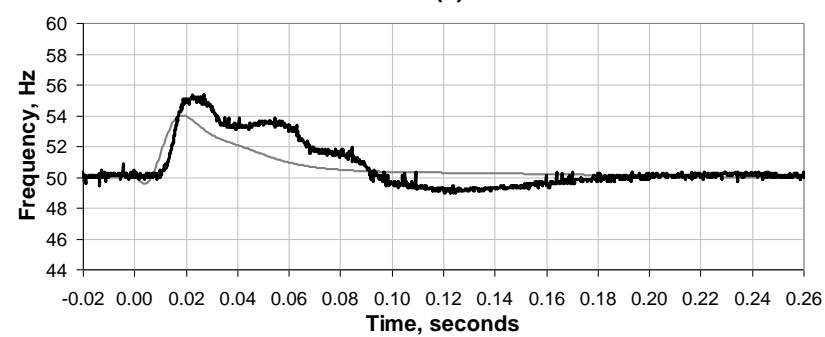

(d)

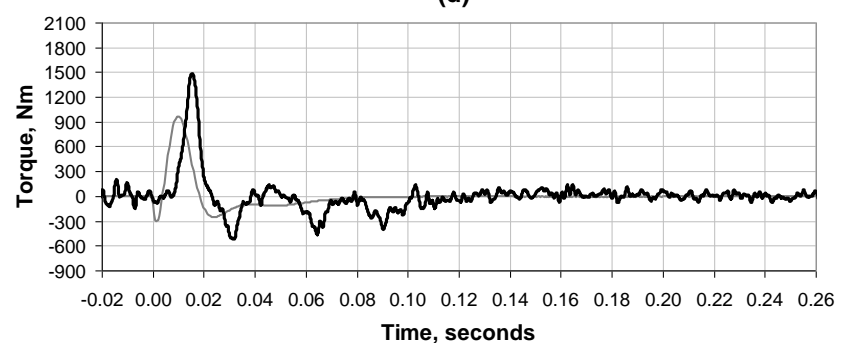

(e)

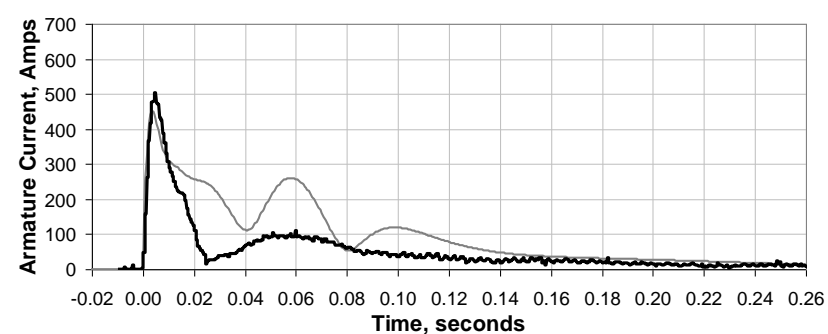

(f)

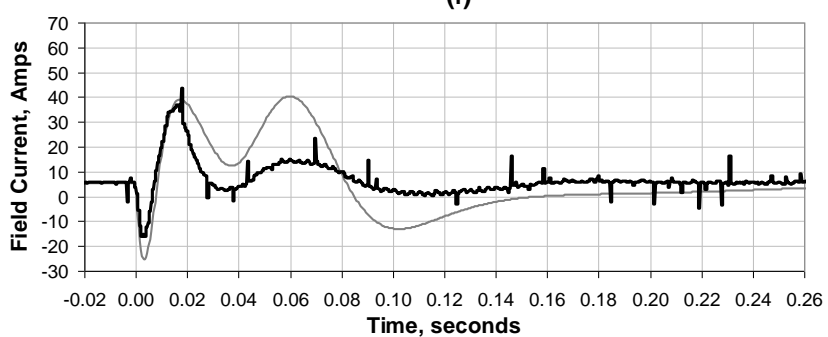

(g)

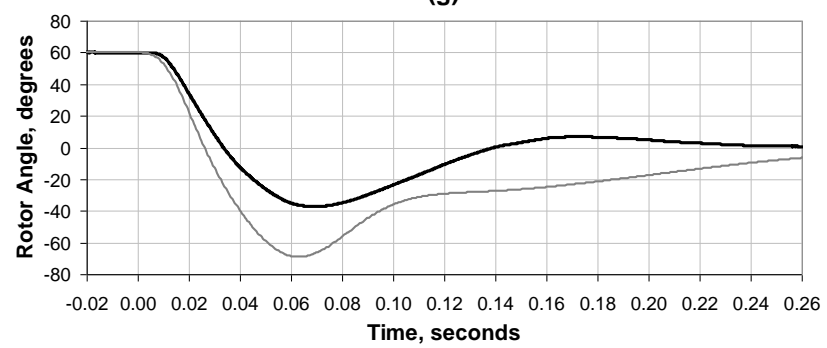

(h)

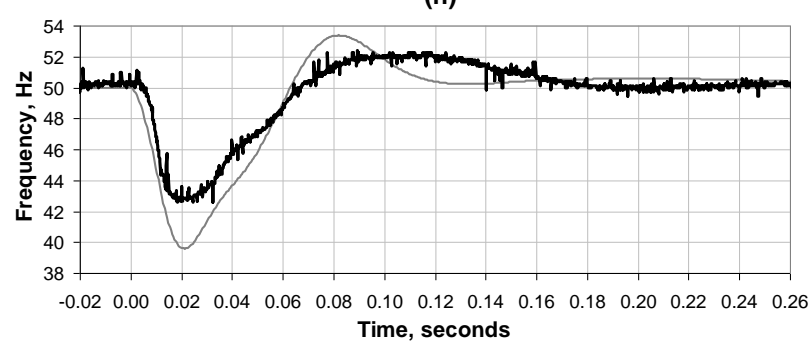

(i)

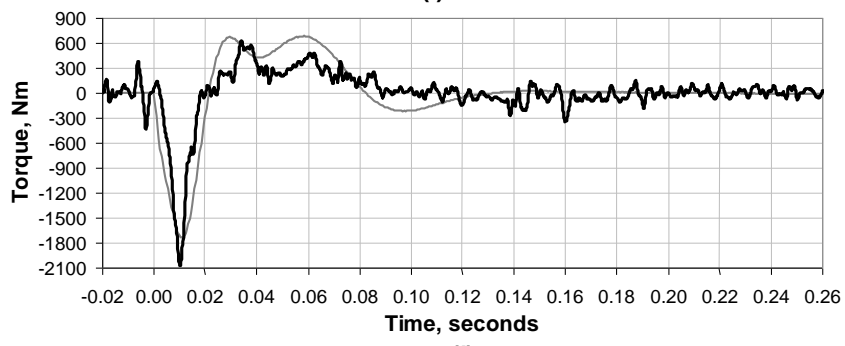

(j)

Fig. 5 Comparison of simulation and experiment results for $60^{\circ}$ synchronizations

Rotor lagging mains synchronization

$a$ Resultant armature current

$b$ Field winding current

$c$ Rotor angle

d Rotor frequency

$e$ Torque

Rotor leading mains synchronization

$f \quad$ Resultant armature current

$g$ Field winding current

$h$ Rotor angle

$i$ Rotor frequency

$j$ Torque 


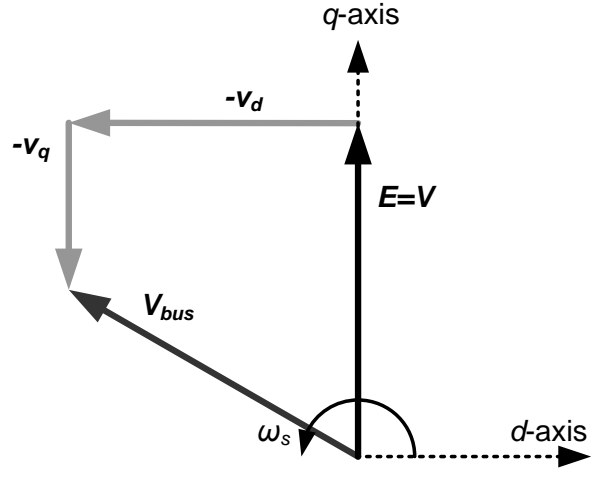

(a)

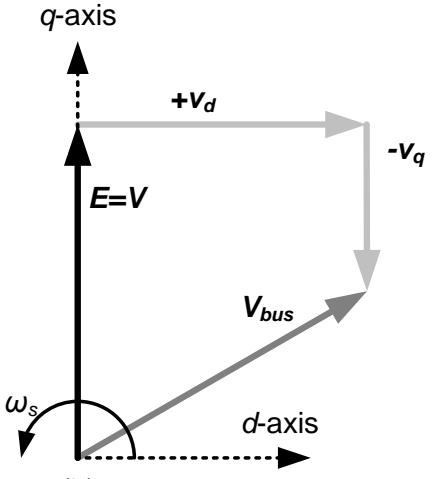

(b)

Fig. 6 Phasor diagram of voltage shift for unloaded alternator leading and lagging by $60^{\circ}$

$a$ Rotor lagging mains synchronization

$b$ Rotor leading mains synchronization 


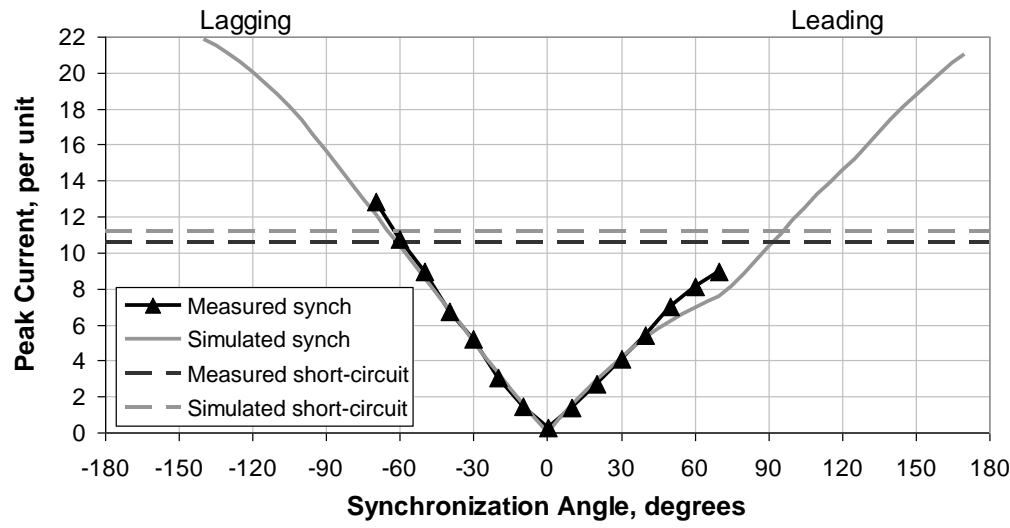

(a)

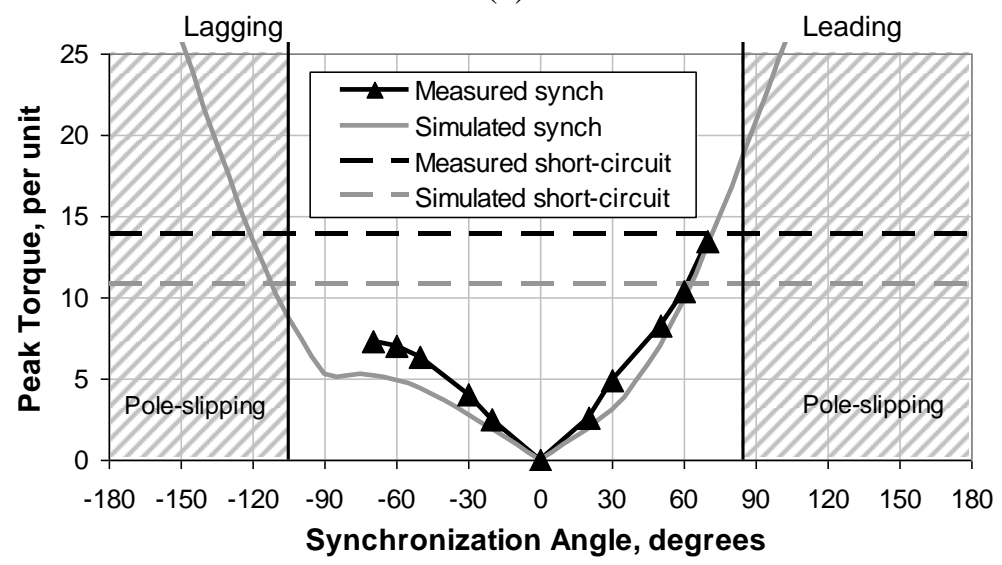

(b)

Fig. 7 Peak current and torque measurements versus synchronization angle for the $31.5 \mathrm{kVA}$ alternator $a$ Peak current $b$ Peak torque 


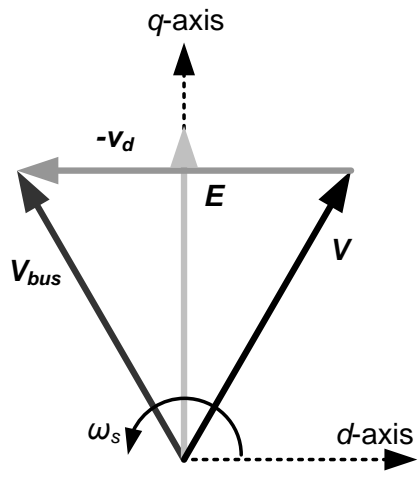

(a)

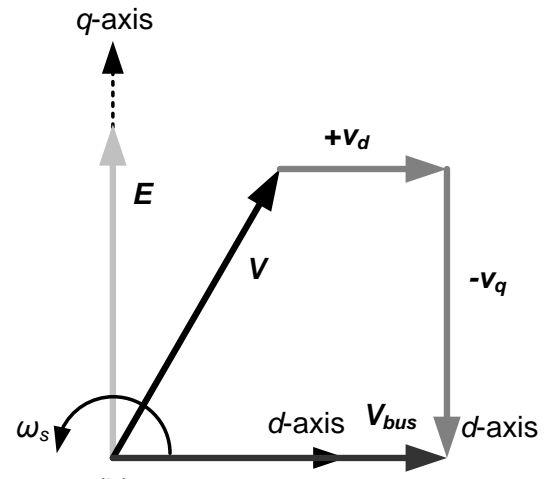

(b)

Fig. 8 Phasor diagram to show $60^{\circ}$ synchronizations for alternator with $30^{\circ}$ load angle $a$ Rotor lagging mains synchronization $b$ Rotor leading mains synchronization 


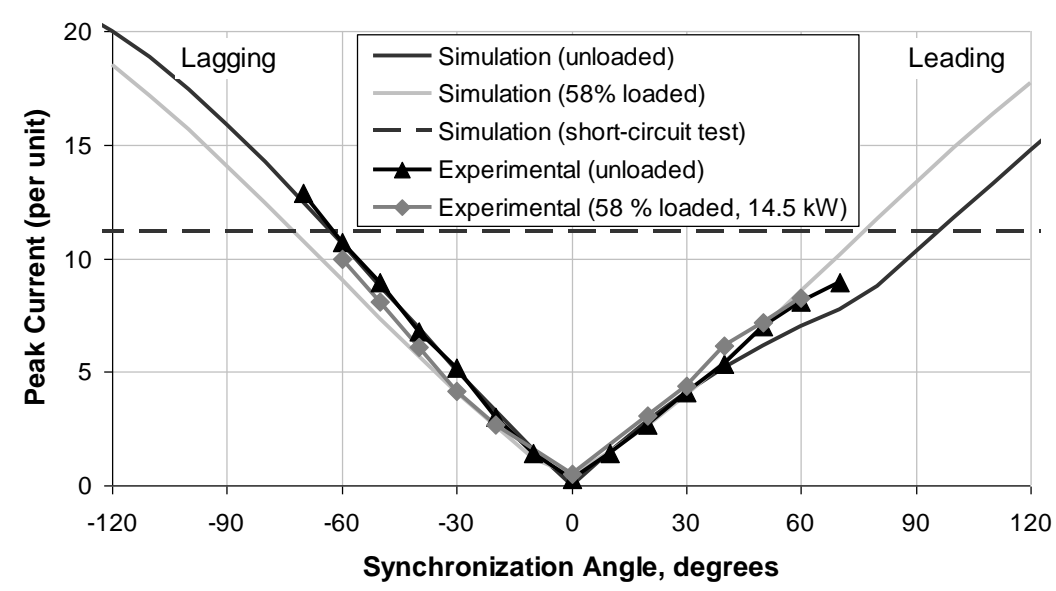

(a)

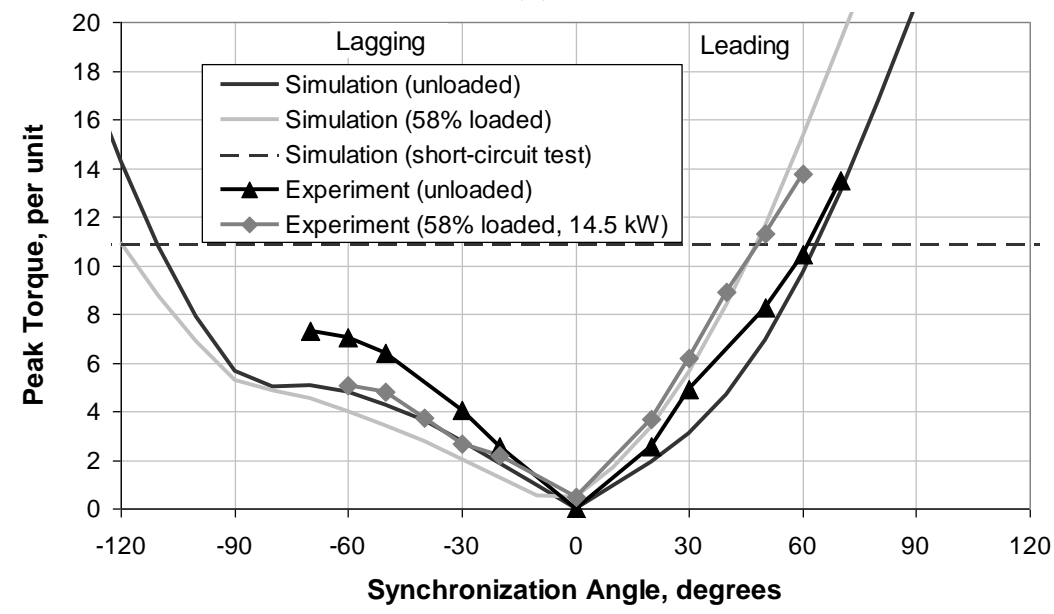

(b)

Fig. 9 Effect of machine loading on synchronization

$a$ Peak current

$b$ Peak torque 


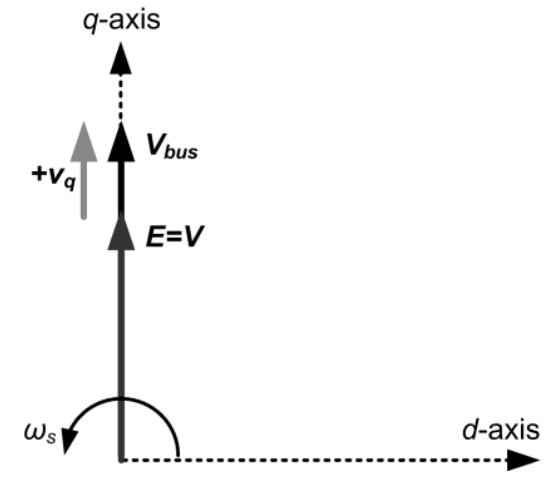

Fig. 10 Synchronization with alternator voltage at $0.75 \mathrm{pu}$ of bus voltage 


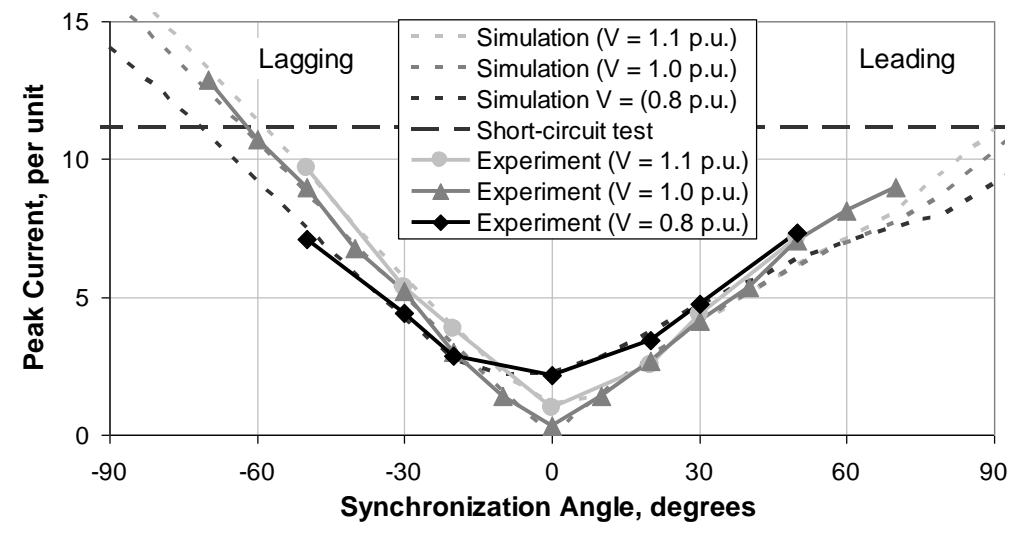

(a)

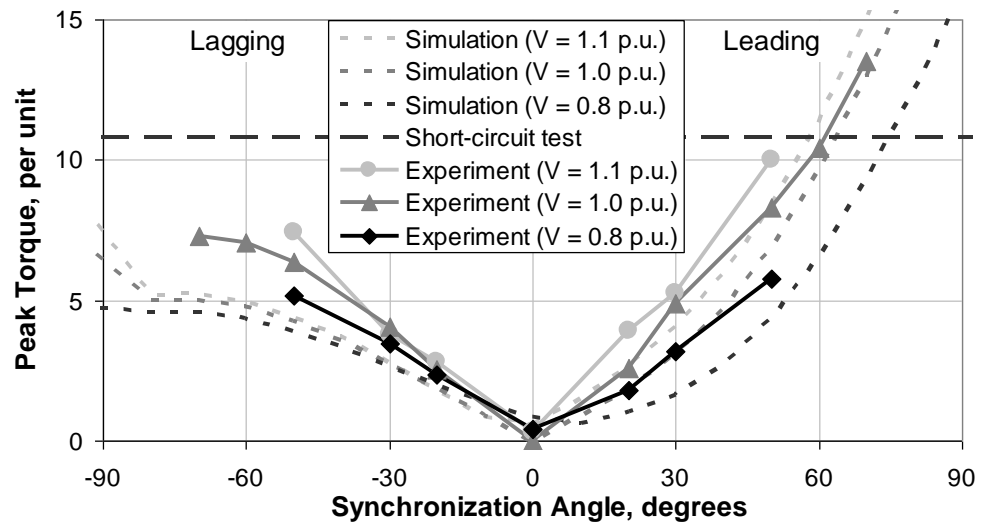

(b)

Fig. 11 Effect of alternator voltage on synchronization

$a$ Peak current

$b$ Peak torque 


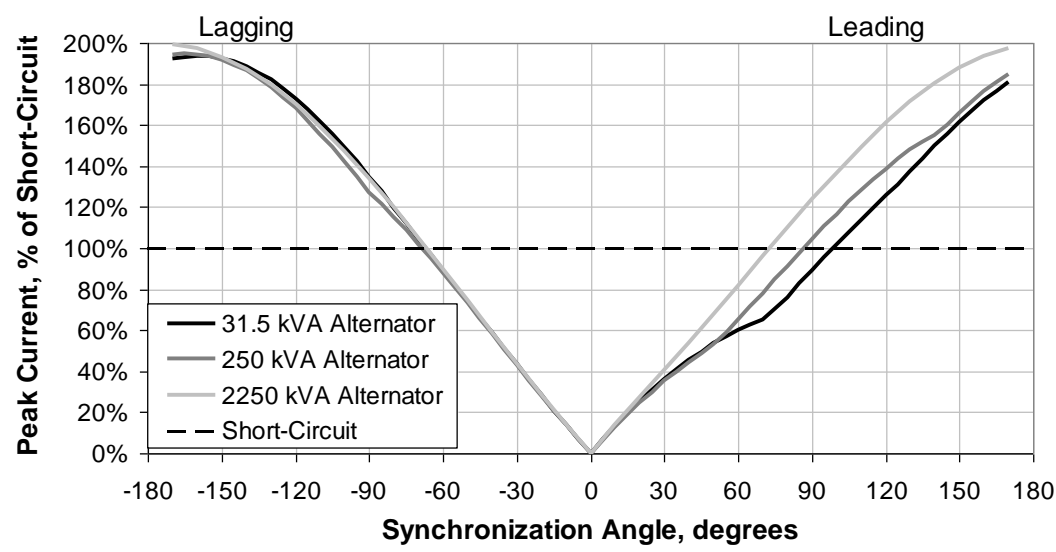

(a)

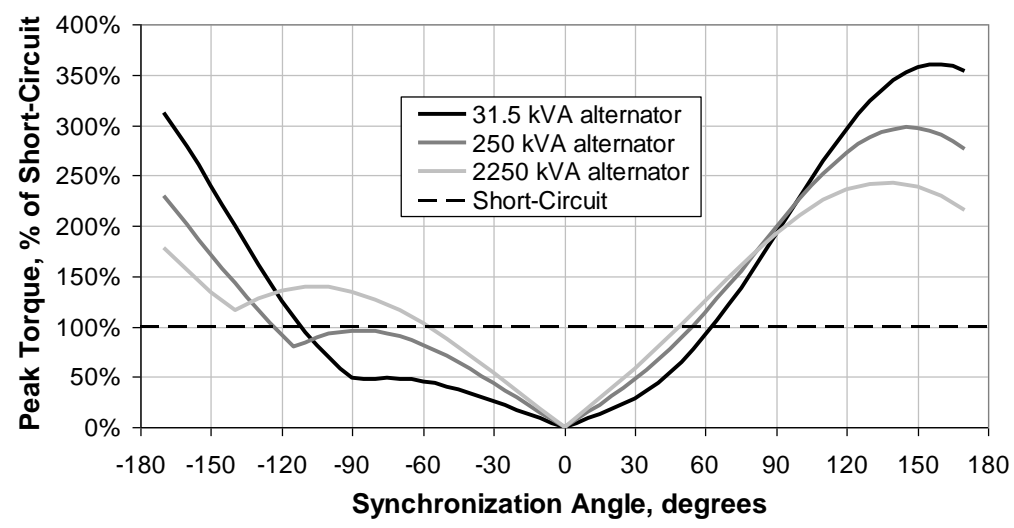

(b)

Fig. 12 Effect of alternator size, $31.5 \mathrm{kVA}$ to $2250 \mathrm{kVA}$, on synchronization

$a$ Peak current normalised to three-phase short-circuit value $b$ Peak torque normalised to three-phase short-circuit value 